\title{
Serum Human Epididymis Protein 4 is a Potential Biomarker for Early Chronic Kidney Disease in an Obese Population
}

This article was published in the following Dove Press journal: Diabetes, Metabolic Syndrome and Obesity: Targets and Therapy

\section{Shubo Tan \\ Yongmao Zeng \\ Shiliang Kuang \\ Jianjun Li}

Department of Urology, Second Affiliated Hospital of the University of South China, Hengyang City, 421000, People's Republic of China
Correspondence: Jianjun $\mathrm{Li}$

Department of Urology, Second Affiliated Hospital of the University of South China,

No. 35, Jiefang Avenue, Zhengxiang

District, Hengyang City, 421000, Hunan

Province, People's Republic of China

Tel +861301734996

Email liundefy666@I26.com
Background: At present, it is difficult to clinica diagnose ear bidney disease (CKD). As a novel biomarker of malignancies the fe reproductive tract, the human epididymis protein 4 (HE4) has been repor to bo aficantly pressed in CKD patients. Aim: We sought to assess whether HE4 $o$ re used as a $\mathrm{A}$ nti somarker of early-stage CKD. Methods: The association between am $\mathrm{h}$ Vevels and $\mathrm{C} D$ was analyzed in a retrospective study. A cohort of 506 patients with diabetic hropathy who were hospitalized at Weihai Central Hospital, China, from anuary 2016 to Novo ber 2019 were included.

Results: Serum HE4 leve were increas with increasing stage of CKD and significantly elevated in patients with C Q 2-5 than Cl $1-2(P<0.001)$. In multivariate linear regression analyses, HE4 levels were s. gly cor ated with the estimated glomerular filtration rate (eGFR) in CKD Atm (Model 2, - 0.001). HE4 (area under the curve; AUC $=0.934$ ) had better diagnostic lue tr creatinine $(\mathrm{SCr} ; \mathrm{AUC}=0.770)$ and blood urea nitrogen (BUN; incr sed $w$ increa $n g$ glomerular lesion (GL) and renal interstitial fibrosis (IF)/tubular sphy ( $\mathrm{T} /$ coores in $1 \mathrm{CKD}$ patients $(P<0.001)$.

Co. " on: SerumrHE4 levels can be positively associated with the severity of CKD and are a valuable clinical biomarker for predicting early-stage CKD.

Keywords iomarker, chronic kidney disease, obese, human epididymis protein 4

\section{Introduction}

Chronic kidney disease (CKD) is a serious health problem worldwide. With increasing prevalence, $\mathrm{CKD}$ has enormous social and economic consequences in our society. ${ }^{1-3}$ However, most early-stage CKD patients have no obvious clinical symptoms, and the clinical indicators of renal function, such as serum creatinine (SCr) and blood urea nitrogen (BUN) levels, do not exceed the normal range because of the strong compensatory ability of the kidney. It is difficult to detect the reduction in renal function at an early stage by traditional urine and blood tests, which hampers the timely diagnosis and treatment for early-stage CKD patients. ${ }^{4}$

In 1991, the human epididymis protein 4 gene located on chromosome 20q12-13.1 was successfully cloned by Kirchhoff et al in the human epididymal epithelium, and the authors discovered that human epididymis protein 4 (HE4), encoded by the gene, is involved in the maturation of sperm. ${ }^{5,6}$ The immature HE4 protein contains two four-disulfide core domains (WFDC2) with antiproteinase activity, and mature HE4 is a 20-25 kDa glycoprotein found in the cytoplasm, cell membrane and circulation., ${ }^{7,8}$ 
HE4 is moderately or highly expressed in ovarian and endometrial cancer, breast cancer and pancreatic cancer., ${ }^{9,10}$ Meanwhile, studies have also shown that HE4 is expressed in normal tissues of the human body, including the kidney, digestive tract, and other organs. ${ }^{11,12}$

Thus far, the significance of HE4 in the context of CKD has not been extensively studied. Only several studies have shown that serum HE4 levels are elevated in CKD. ${ }^{13,14}$ It is uncertain whether HE4 could be a sufficiently sensitive marker to distinguish patients with early-stage CKD from healthy individuals. Accordingly, in this study, we studied whether serum HE4 can be used as a sensitive and specific indicator for predicting early-stage CKD. We additionally investigated the association of HE4 levels with pathological changes in CKD patients.

\section{Materials and Methods Study Population}

Because most of the patients in the study have been discharged and cannot be contacted, for research needs, the Ethics Committee of Renmin Hospital of Weihai Central Hospital approved this retrospective study and the requirement for informed consent was waived according to th guidelines of the Declaration of Helsinki. In this study, th privacy of the included patients is strictly confidential and will not have any impact on the patients. te nical characteristics of all subjects enrolled in as stud were obtained by medical record review. Th of 506 obese patients with CKD (b y mass is x [BMI] $\geq 28$ ) who were hospitalized at en Central h pital, Weihai, China from January 2016 to No nber 2019: 487 patients without kidney disease (CKD serving as a control group. Pa nts wi neoplastic diseases, or other serious diseases $m$ cluded cluding 9 patients with severe li 0 ing on ase or ovarian cancer or other malig ant dise es.

\section{Inclusion Ch, rria, Definition of CKD}

Inclusion criteria was $\mathrm{ased}$ on the definitions for CKD according to the KDIGO guidelines: ${ }^{15}$ "CKD is defined as abnormalities of kidney structure or function, present for $>3$ months". Thus, the diagnosis of CKD was made when estimated glomerular filtration rate was reduced (eGFR $\leq 60 \mathrm{~mL} / \mathrm{min} /$ $1.73 \mathrm{~m}^{2}$ ) and/or signs of kidney damage were present. Kidney damage was ascertained by kidney disease proven by kidney biopsy, pathological hematuria and proteinuria or abnormal imaging examination results (computed tomography, ultrasound, magnetic resonance imaging or nuclear imaging). According to the classification of the KDIGO guideline ${ }^{15}$ the included $506 \mathrm{CKD}$ patients were divided into five subgroups according to their eGFR values: $\mathrm{CKD} 1, \mathrm{eGFR}>90 \mathrm{~mL} / \mathrm{min} / 1.73 \mathrm{~m}^{2}$; CKD2, eGFR $=61-90 \mathrm{~mL} /$ $\mathrm{min} / 1.73 \mathrm{~m}^{2}$; CKD3, eGFR=31-60 mL/min $/ 1.73 \mathrm{~m}^{2}$; CKD4, eGFR $=16-30 \mathrm{~mL} / \mathrm{min} / 1.73 \mathrm{~m}^{2}$; and CKD5, eGFR $<15 \mathrm{~mL} /$ $\min / 1.73 \mathrm{~m}^{2}$. Early CKD (CKD1-2) was defined as an eGFR $>60 \mathrm{~mL} / \mathrm{min} / 1.73 \mathrm{~m}^{2}$. Advanced CKD (CKD3-5) was defined as eGFR $\leq 60 \mathrm{~mL} / \mathrm{min} / 1.73 \mathrm{~m}^{2}$. We included $487 \mathrm{CKD} 0$ patients without a medical history of $P$ nd/or a eGFR $<60 \mathrm{~mL} / \mathrm{min}$. Emission computed omograph $(\mathrm{eCT})$ has been considered the gold standara clinical $\mathrm{m}$ surement of eGFR. In this study, the ef all CKD tients was measured by eCT.

\section{Evaluation HE4 in Clin al Practice}

We collectec tota $102 \mathrm{CKD}$ atients who had undergone eCT examination at hospital from January 2020 to June 020 . We calculatearhe sensitivity and specificity of HE to verify the alue of serum HE4 for diagnosis of early CKL In addition of further confirm the relationship between HE4 an NUD also collected a total of 51 CKD patients w. had undergone renal biopsy at our hospital from uary 2016 to November 2019, and evaluated whether serum HE4 concentrations were associated with pathological anges in CKD. All patients with malignant tumors were excluded.

\section{Measurement of HE4 Levels}

Serum samples were prepared immediately by centrifugation of peripheral venous blood and cryopreserved $\left(-80^{\circ} \mathrm{C}\right)$ for the determination of HE4 levels. Serum levels of HE4 were measured by electrochemiluminescence immunoassays (Cobas e 601, F. Hoffmann-La Roche Ltd, Basel, Switzerland). The samples with HE4 concentrations over $1500 \mathrm{pmol} / \mathrm{L}$ were measured again (precision, coefficient of variation $[\mathrm{CV}]<5 \%$; analytic measurement range, from 15 to $1500 \mathrm{pmol} / \mathrm{L}$; detection limit, $5 \mathrm{pmol} / \mathrm{L}$ ).

\section{Laboratory Measurements and Definitions}

Blood samples were collected from the patients after they had fasted overnight for at least 8 hours. SCr, BUN, beta 2 microglobulin ( $\beta 2-\mathrm{MG})$, cystatin $\mathrm{C}(\mathrm{Cys})$, uric acid (UA), hemoglobin ( $\mathrm{Hb}$ ) and albumin (ALB) levels were 
measured using a Siemens ADVIA 2400 automatic biochemistry analyzer (Siemens AG).

\section{Renal Biopsy and Histopathological Staining}

In this study, renal biopsy was performed in 51 of $506 \mathrm{CKD}$ patients. Pathologic materials were processed by conventional histological procedures. The pathologic samples were used to evaluate glomerular, renal tubular, and interstitial conditions by hematoxylin and eosin (H\&E) and Periodic SchiffMethenamine (PASM) staining in the pathology department of our hospital. The CKD scores were evaluated according to the 2007 Banff classification. ${ }^{16,17}$ The score for glomerular lesion (GL) was based on the percentage of diseased glomeruli as follows: GL0, GL $=0 \%$ diseased glomeruli; GL1, $\leq 25 \%$; GL2, 25-50\%; and GL3: $>50 \%$. The score for renal interstitial fibrosis (IF)/tubular atrophy (TA) was based on the percentage of cortical parenchymal involvement as follows: IF/TA0, IF/ $\mathrm{TA} \leq 5 \%$ cortical area; IF/TA1: 6-25\%; IF/TA2; 26-50\%; and IF/TA $3:>50 \%$.

\section{Statistical Analyses}

The data with normal distributions were expressed as the mean \pm standard deviation (SD). Comparisons between va bros with normal distributions were performed by $t$ test or ana of variance (ANOVA). The data that were $r$ nally tributed were expressed by median (inter artile ra se [IQR and were analyzed by the Mann-Whitney test cunnes Wallis test. The distribution of cr gorical v. ables was studied using the Chi-square tes the variate line regression modeling was performed with HE4 as . independent variable and eGFR as the dep cent variable. To st if HE4 might distinguish betwee $\mathrm{CKD} 0 \mathrm{~d}$ early $\mathrm{CKD}$, the diagnostic

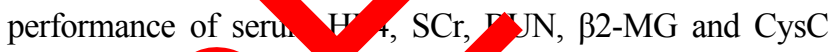
levels for $\mathrm{C}^{y}$ dete ined ng receiver operating characteristir ROC) $\mathrm{C}$ ves, and isitivity, specificity, area under the curv $95 \%$ confidence intervals were calculated. A SPSS 24.0 was used for the statistical analyses. P-values ss than 0.05 were considered statistically significant.

\section{Result}

\section{Clinical Characteristics of the Study Population}

Serum HE4 levels in the CKD patients were significantly higher than control subjects (CKD0, data not shown). The clinical characteristics of all CKD subjects are presented in
Table 1. All patients were divided into two groups including patients with CKD1-2 and patients with CKD3-5. All variables were compared between the two groups. The disease history of the CKD patients was as follows: hypertension in 244 patients, diabetes in 73 patients, primary kidney disease in 146 patients, nephrolithiasis in 83 patients, and other diseases in 22 patients. Median levels of HE4 in patients with CKD1-2 were $267.8 \mathrm{pmol} / \mathrm{L}$. Median levels of HE4 CKD3-5 were only $578.8 \mathrm{pmol} / \mathrm{L}$. Significantly, The serum levels of HE4 were significantly higher in patients with CKD3-5 th hat in patients with CKD1-2 $(P<0.001)$.

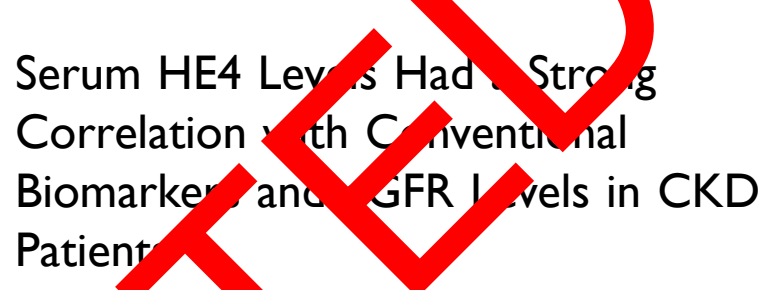

In order to cla the relationship between serum HE4 le renal to tion in CKD patients, multivariate near regression analysis was performed. Multivariate nalysis reve led that HE4 levels remained significantly a strongly ssociated with eGFR after adjusting for age, genau, 1 II, admission systolic blood pressure (SBP), ission diastolic blood pressure (DBP), current smoker, current drinker and CKD etiology and laboratory measurements (Table 2). In the model 3, these factors explained $87.5 \%$ of the variance in eGFR.

\section{Serum HE4 Levels Had a Better Diagnostic Value Than SCr, $\beta 2-M G$ and Cys C Levels for Early-Stage CKD Patients}

To determine the performance of HE4 as a diagnostic biomarker for early $\mathrm{CKD}$, we performed the area under the receiver operating characteristic curve (ROC-AUC) analysis (Table 3). Serum HE4 (AUC $=0.982,95 \%$ CI: $0.974-0.999$, optimal cutoff $67.6 \mu \mathrm{mol} / \mathrm{L}$, sensitivity $94.9 \%$, and specificity $98.4 \%$ ) had better diagnostic performance than $\mathrm{SCr}$ (AUC $=0.912,95 \%$ CI: 0.884-0.935, optimal cutoff $66.3 \mu \mathrm{mol} / \mathrm{L}$, sensitivity $76.3 \%$, and specificity 96.7\%) and BUN (AUC $=0.834$, 95\% CI: $0.812-$ 0.856 , optimal cutoff $6.9 \mu \mathrm{mol} / \mathrm{L}$, sensitivity $61.1 \%$, and specificity $92.6 \%$ ) for patients with CKD1-5. The AUC for HE4 was 0.934 (95\% CI: 0.925-0.967) for differentiating patients with CKD1-2 from CKD0, with an optimal cutoff value of $63.7 \mathrm{pmol} / \mathrm{L}$ (sensitivity $88.7 \%$ and specificity 98.1\%). HE4 had a better diagnostic value than $\mathrm{SCr}$ 
Table I Clinical Characteristics of CKD Patients

\begin{tabular}{|c|c|c|c|c|}
\hline Variables & CKDI-5 (n=506) & CKDI-2 (n=235) & CKD3-5 (n=27I) & $P$ value \\
\hline Age (Years) & $64.6 \pm 9.4$ & $65.4 \pm 10.6$ & $63.7 \pm 8.1$ & 0.151 \\
\hline Gender (male), n (\%) & $301(59.5)$ & $146(61.6)$ & $155(57.2)$ & 0.194 \\
\hline BMI $\left(\mathrm{kg} / \mathrm{m}^{2}\right)$ & $28.8 \pm 4.2$ & $25.6 \pm 3.1$ & $32.9 \pm 5.2$ & $<0.001$ \\
\hline Admission SBP $(\mathrm{mmHg})$ & $144(13 \mid-136)$ & $139(129-134)$ & $149(133-167)$ & $<0.001$ \\
\hline Admission DBP (mmHg) & 85 (77-92) & $83(73-87)$ & $89(80-96)$ & 0.003 \\
\hline Current smoker, n (\%) & $64(12.6)$ & $29(12.3)$ & $35(12.9)$ & 0.407 \\
\hline Current drinker, n (\%) & $122(24.1)$ & $57(24.2)$ & $65(24.0)$ & 0.905 \\
\hline CKD Etiology & - & & & \\
\hline Hypertension, n (\%) & $244(48.2)$ & $101(43.0 \%)$ & $143(52.8 \%)$ & 0.001 \\
\hline Diabetes, n (\%) & $73(14.4)$ & $20(8.5 \%)$ & $53(19.5 \%)$ & \\
\hline Nephrolithiasis, n (\%) & $83(16.4)$ & $43(18.3 \%)$ & & 032 \\
\hline Primary kidney disease, n (\%) & $146(28.9)$ & $57(24.3 \%)$ & & 10 \\
\hline Other diseases, n (\%) & $22(4.3)$ & $10(4.25 \%)$ & & \\
\hline \multicolumn{5}{|l|}{ Laboratory measurements } \\
\hline $\mathrm{SCr}(\mu \mathrm{mol} / \mathrm{L})$ & $175(149-284)$ & $131(124-165)$ & & $<0.001$ \\
\hline BUN (mmol/L) & $6.4(4.1-8.7)$ & $5.8(3.7-6.3)$ & & $<0.001$ \\
\hline eGFR $\left(\mathrm{mL} / \mathrm{min} / \mathrm{l} .73 \mathrm{~m}^{2}\right)$ & $75.3(57.2-87.9)$ & $98.2(86.3-104.5)$ & & $<0.001$ \\
\hline $\mathrm{Hb}(\mathrm{g} / \mathrm{L})$ & $96(81-110)$ & $106(94-123)$ & ) & $<0.001$ \\
\hline $\mathrm{UA}(\mu \mathrm{mol} / \mathrm{L})$ & $391(352-518)$ & $355(312-490$ & $4-569)$ & $<0.001$ \\
\hline ALB $(g / L)$ & $35.4(28.5-38.4)$ & $37.5(29.8,0.1)$ & $33.6(-7.6-36.8)$ & $<0.001$ \\
\hline HE4 (pmol/L) & $398.6(287.5-679.4)$ & $267.8(144-395.8)$ & $578.8(4|5.7-10| 8.3)$ & $<0.001$ \\
\hline
\end{tabular}

Note: Normally distributed data are presented as the mean \pm SD, non-normally distributed da presented a he median (interquartile range), and categorical variables are presented as the $\mathrm{n}(\%)$.

Abbreviations: CKD, chronic kidney disease; BMI, body mass index; SBP, syst nitrogen; eGFR, estimated glomerular filtration rate; HE4, human epididymis pro

(AUC $=0.770,95 \%$ CI: $0.724-0.840$, optimal $\mu \mathrm{mol} / \mathrm{L}$, sensitivity $53.4 \%$, and specifici BUN (AUC $=0.647,95 \%$ CI: 0.601-0724, tiv $5.87 \mathrm{mmol} / \mathrm{L}$, sensitivity $45.4 \%$, an secificity $6 \%$ ) for patients with CKD1-2.

To further investigate $t^{y}$ diagnostio erformance of serum HE4 in early $\mathrm{CK}$ patients, we mea ared $\beta 2-\mathrm{MG}$ and $\mathrm{CysC}$ levels in 8 \& $506 \mathrm{KD}$ patients. Serum HE4 had significantly hatter dh, ostic pe mance for CKD12 patients thar s-M and C. ata not shown), both of which har been $c$,firmed to be useful indicators for early kidney a ses. ${ }^{18-21}$

Lolic blood pressure; $\mathrm{SCr}$, serum creatinine; $\mathrm{BUN}$, blood urea in 4; moglobin; UA, uric acid; ALB, albumin.

Table 2 The Relations Between the HE4 Level and eGFR in CKD Patients

\begin{tabular}{|l|c|c|c|}
\hline Variables & Crude & Model I & Model 2 \\
\hline $\mathrm{R}^{2}$ & 0.787 & 0.797 & 0.875 \\
$\mathrm{~S} \beta$ & -0.864 & -0.870 & -0.808 \\
$(95 \% \mathrm{Cl})$ & $-0.907--0.822$ & $-0.912--0.828$ & $-0.854-0.761$ \\
$P$ value & $<0.001$ & $<0.001$ & $<0.001$ \\
\hline
\end{tabular}

Notes: Crude: Adjusted for none. Model 2: Adjusted for age, gender, BMI, admission SBP, admission SBP, current smoker, current drinker and CKD Etiology. Model 3: Adjusted for age, gender, BMI, admission SBP, admission SBP, current smoker, current drinker and CKD etiology and laboratory measurements.

Abbreviations: eGFR, estimated glomerular filtration rate; CKD, chronic kidney disease; HE4, human epididymis protein 4; BMI, body mass index; SBP, systolic blood pressure; DBP, diastolic blood pressure; $\mathrm{S} \beta$, standardized $\beta ; \mathrm{Cl}$, confidence interval. 
Table 3 Diagnostic Ability of Serum HE4 Values to Assess CKD

\begin{tabular}{|c|c|c|}
\hline Variables & AUC & $95 \% \mathrm{Cl}$ \\
\hline \multicolumn{3}{|l|}{ CKDI-5 } \\
\hline HE4 (pmol/L) & 0.982 & $0.974-0.99$ \\
\hline $\mathrm{SCr}(\mu \mathrm{mol} / \mathrm{L})$ & 0.912 & $0.884-0.93$ \\
\hline BUN (mmol/L) & 0.834 & $0.812-0.85$ \\
\hline \multicolumn{3}{|l|}{ CKDI-2 } \\
\hline HE4 (pmol/L) & 0.934 & $0.925-0.96$ \\
\hline $\mathrm{SCr}(\mu \mathrm{mol} / \mathrm{L})$ & 0.770 & $0.724-0.84$ \\
\hline BUN (mmol/L) & 0.647 & $0.60 \mathrm{I}-0.72$ \\
\hline \multicolumn{3}{|l|}{ CKD3-5 } \\
\hline HE4 (pmol/L) & 0.955 & $0.96-1.000$ \\
\hline $\mathrm{SCr}(\mu \mathrm{mol} / \mathrm{L})$ & 0.903 & $0.873-0.97$ \\
\hline BUN (mmol/L) & 0.805 & $0.756-0.87$ \\
\hline \multicolumn{3}{|c|}{$\begin{array}{l}\text { Abbreviations: CKD, chronic kidney disease; HE4, human epididymis protein } 4 \text {; } A \\
\text { urea nitrogen. }\end{array}$} \\
\hline
\end{tabular}

To investigate whether serum HE4 levels were associated with pathological changes in CKD, we categorized 51 of 506 CKD patients with renal insufficiermy of different degrees from early to advanced stages wh hau undergone renal biopsy into four groups accordin to their GL and IF/TA scores. Indeed, serur $\mathrm{AL} \mathrm{SCr}$ a BUN levels increased with incr sing $C /$ score $\left(P<0.001\right.$, Table 5). Serum $\mathrm{HS}_{4}$, el were mo strongly and positively corr wed with $₹ / \mathrm{TA}$ scores $(P<0.001$; Table 6), whic cur explaine the close positive relationship be teen HE4 hals and renal function in CKD patien

\begin{tabular}{|c|c|c|c|}
\hline & Cutoff & $\begin{array}{c}\text { Sensitivity } \\
\text { (\%) }\end{array}$ & $\begin{array}{c}\text { Specificity } \\
\text { (\%) }\end{array}$ \\
\hline \multicolumn{4}{|l|}{ CKDI-2 } \\
\hline HE4 (pmol/L) & 63.7 & 94.6 & 86.7 \\
\hline $\mathrm{SCr}(\mu \mathrm{mol} / \mathrm{L})$ & 65.4 & 60.3 & 85.4 \\
\hline $\mathrm{BUN}(\mathrm{mmol} / \mathrm{L})$ & 5.87 & 51.1 & 82.3 \\
\hline \multicolumn{4}{|l|}{ CKD3-5 } \\
\hline HE4 (pmol/L) & 106.4 & 93.5 & 99.7 \\
\hline $\mathrm{SCr}(\mu \mathrm{mol} / \mathrm{L})$ & 87.0 & 87.2 & 89.4 \\
\hline BUN (mmol/L) & 6.1 & 79.5 & 82.2 \\
\hline
\end{tabular}

Abbreviations: CKD, chronic kidney disease; HE4, human epididymis protein 4; $\mathrm{SCr}$, serum creatinine; BUN, blood urea nitrogen.

\section{Discus in}

The new and in ortant findings from this study were (1) ser vels of $\mathrm{H}_{\downarrow}$ were significantly higher in patients ith CKD than in control subjects; (2) serum HE4 levels vere strong1. correlated with eGFR according to the mulriate lin regression analyses; (3) serum HE4 had high - uvity and specificity for predicting CKD1-2; (4) serum HE4 levels had a strong and positive correlation with GL and IF/TA scores in CKD patients.

GFR is the best indicator of renal function in CKD and is measured as the clearance rate of a filtration marker from serum by the kidneys. ${ }^{22}$ However, accurate measurements of GFR by inulin and nuclear medicine measurements require the appropriate infrastructure and are time consuming. $\mathrm{SCr}$ is not sensitive or specific for diagnosing early renal insufficiency, making it difficult for clinicians to timely prevent and treat early CKD. At present, clinical practice faces the challenge of detecting the early stages of CKD. No biomarker exists that reliably detects the early stages of CKD. $\beta 2-\mathrm{MG}$ and $\mathrm{CysC}$ have been investigated as alternative markers of kidney function to estimate GFR with similar precision as $\mathrm{SCr}$ and with less bias due to muscle mass. ${ }^{23,24}$ However, age, gender, smoking, race and other factors influence serum CysC concentrations and reduce its reliability as a biomarker for diagnosing early CKD. ${ }^{23,25}$ Serum $\beta 2-M G$ levels can reflect GFR well, but it is also influenced by many factors in early CKD. ${ }^{24}$ Kidney injury molecule-1 (KIM-1), interleukin-18 (IL-18), neutrophil and gelatinase-associated lipocalin (NGAL) are considered biomarkers for acute kidney injury (AKI), but are limited in their use for early CKD. ${ }^{26-29}$ 
Table 5 Major Laboratory Indicators According to Glomerular Lesion Scores in CKD Patients

\begin{tabular}{|l|c|c|c|c|}
\hline Variables & GL0 (n=I7) & GLI (n=I4) & GL2 (n=I I) & GL3 (n=9) \\
\hline eGFR $\left(\mathrm{mL} / \mathrm{min} / \mathrm{I} .73 \mathrm{~m}^{2}\right)$ & $57.1(49.2-68.6)$ & $50.6(46.4-64.5)$ & $42.7(36.5-55.8)$ & $29.2(24.9-42.6)$ \\
HE4 (pmol/L) & $85.3(66.4-101.3)$ & $170.42(137.6-236.0)$ & $245.7(118.8-559.4)$ & $492.5(155.6-799.2)$ \\
\hline
\end{tabular}

Abbreviations: CKD, chronic kidney disease; GL, glomerular lesion; SCr, serum creatinine; BUN, blood urea nitrogen; HE4, human epididymis protein 4.

Table 6 Major Laboratory Indicators According to the Renal Interstitial Fibrosis/Tubular Atrophy Scores in CKD Patients

\begin{tabular}{|c|c|c|c|c|c|}
\hline Variables & IF/TAO $(n=19)$ & IF/TAI $(n=\mid 5)$ & IF/TA2 $(n=9)$ & IF/TA3 (n=8) & $P$ value \\
\hline eGFR $\left(\mathrm{mL} / \mathrm{min} / \mathrm{I} .73 \mathrm{~m}^{2}\right)$ & $64.2(56.2-73.5)$ & $53.6(42.7-65.1)$ & $46.2(41.0-60.4)$ & $39.6(38.5-47.6)$ & $<0.001$ \\
\hline HE4 (pmol/L) & $73.8(54.6-81.7)$ & 143.6 (105.6-183.5) & 203.7 (137.2-625.8) & 399.8 (183.6-on & $<0.001$ \\
\hline
\end{tabular}

Abbreviations: CKD, chronic kidney disease; IF, interstitial fibrosis; TA, tubular atrophy; SCr, serum creatinine; BUN, blood urea nitrogen: A, human epic protein 4.

Recently, urinary proteomics analysis improved the diagnostic performance to detect early $\mathrm{CKD}^{30,31}$ Unfortunately, this procedure is expensive and complex. A convenient and quick blood test is desirable, making urinary proteomics analysis difficult for routine clinical use.

Our study showed that compared with patients without CKD, serum HE4 levels were significantly elevated in advanced CKD patients. The results of our study are in accordance with the findings of previous studies. ${ }^{32,33}$ Therefore, we further explored the relationship betwe HE4 and early CKD. Importantly, we found that serum levels of HE4 were still significantly higher ients with CKD1 and CKD2 than in CKD0 pati ts. Our tudy showed that serum HE4 had high specificrs, and cilsim ity for predicting patients with $\mathrm{CK}^{\mathrm{D}}-2$, whic uggested that HE4 may be useful for and treatment for early-stage $C X \mathrm{D}$ patien. Moreover, we also found that HE4 b higher diagnos value for patients with CKD1 than $\beta$ MG and $\mathrm{CysC}$, both of which have been used th early mical diagnosis of early kidney d case.

In this dy, acc ding to the optimal cut-off value of $63.7 \mathrm{pmol} / \mathrm{L}$ diagnoss of CKD1-2, we calculated the specificity an ensitivity of HE4 in the tested population without malign, tumors to be high. Although studies have shown that HE4 is also associated with the age of the healthy population, smoking habit, inflammatory diseases, heart failure, etc. ${ }^{34-38}$ HE4 still showed a high specificity for the diagnosis of early CKD in the tested population. Furthermore, HE4 had a sensitivity of $95.7 \%$, and this high sensitivity was very conducive for screening for early CKD. Therefore, the results further confirmed the important value of HE4 for predicting early CKD.
We showed that serum iE4 levo were snificantly and positively associat with sev of GL. The elevated serum HEA la is $\mathrm{j}$ CKD prients may be due to upregulated $\angle 4$ expr ion a roduced eGFR. Because HE as small mol secreting protein, can be filtered freely in 1 glomerulus. ${ }^{7,39}$ Patients with CKD have aculine in rem function, which changes the rem val of HEA in the circulating blood, resulting in incr sed serum IE4, thereby explaining the finding in our St that crum HE4 was strongly correlated with CRR. Moreover, research has shown that HE4 expression apros rated in primary renal disease ${ }^{12}$ which may be associated with the fact that in early CKD, there is no gnificant decrease in renal function, but serum HE4 was significantly increased. Additionally, our results demonstrated that HE4 levels were clearly correlated with the severity of IF/TA. The increased serum HE4 levels may be related to renal fibrosis. HE4 often exhibits antiproteinase activity, indicating an important role of HE4 in fibrosis. ${ }^{40-42}$ Other proteins with WFDC have also been correlated with fibrosis formation and inflammatory processes. ${ }^{41}$ Importantly, these processes play an important role in the progression of CKD. The studies have suggested that HE4 is a mediator of renal fibrosis and when overexpressed, can prevent the degradation of type I collagen by inhibiting Prss 35 and Prss 23 serine protease activities during renal fibrosis. ${ }^{40,41}$ Recently, some researchers have reported that serum HE4 levels were associated with heart failure (HF) and speculated that elevated HE4 levels in patients with HF may be due to cardiac fibrosis. ${ }^{37,38}$ Since renal fibrosis has been involved in the development of CKD at an early stage, it may also give a possible explanation of why the serum levels of HE4 are significantly increased in the early stages of CKD. 


\section{Limitation}

First, our study is a single-center study with a limited sample size and the results cannot be extrapolated. More studies are needed to identify the best HE4 cutoff or recognizing early-stage CKD in other centers or by multicenter studies. Second, this study excluded patients with malignant tumors, which may affect the accuracy of HE4 in detecting renal function in some tumor patients.

\section{Conclusion}

Our findings showed that serum HE4 levels were positively associated with the severity of CKD using two aspects of clinical indexes and renal pathology. HE4 can be considered a very valuable clinical biomarker for predicting early-stage CKD. In the future, multi-center and large sample studies are needed to further confirm the reliability of the research results.

\section{Disclosure}

All the authors declared no conflicts of interest and have nothing to disclose.
11. Hertlein L, Stieber P, Kirschenhofer A, et al. Human epididymis protein 4 (HE4) in benign and malignant diseases. Clin Chem Lab Med. 2012;50(12):2181-2188. doi:10.1515/cclm-2012-0097

12. Galgano MT, Hampton GM, Frierson HF. Comprehensive analysis of HE4 expression in normal and malignant human tissues. Mod Pathol. 2006;19(6):847-853. doi:10.1038/modpathol.3800612

13. Huang Y, Jiang H, Zhu L. Human epididymis protein 4 as an indicator of Acute Heart failure in patients with chronic kidney disease. Lab Med. 2020;51(2):169-175. doi:10.1093/labmed/lmz041

14. Yuan T, Li Y. Human epididymis Protein 4 as a potential biomarker of chronic kidney disease in female patients with normal ovarian function. Lab Med. 2017;48(3):238-243. doi:10.1093/labmed/lmx036

15. KDIGO 2012 clinical Practice guideline for the evaluation and management of chronic kidney disease. Kidney Int Suppl. 2013;3.

16. Levey AS, Stevens LA, Schmid A new equation to estimate glomerular filtration ro Ann th Med. 2009;150 (9):604-612. doi:10.7326/0003 19-150-9-200 050-00006

17. Solez K, Colvin RB, Racusen LC, 1. Banff $07 \mathrm{cl}$ ification of renal allograft pathology: upda and fur directions $4 \mathrm{~m} J$ Transplant. 2008;8(4):753-760. do J.1111/j.1600-0 3.20 02159.x

18. Deinum J, Derkx FH -ystatin fo stimation somerular filtration rate? Lancet. 2000;356924_ 624 5. doi:10.1016/S0140-6736(00)03152-4

19. Coll E, Bote, Alvan et al. Se cystatin C as a new marker for nonip ive estimat of nerular filtration rate and as a marl fo arly renal in, nent. Am J Kidney Dis. 2000;36 (1):29-34. doi: 053/ajkd.2000.8237

20. Lim S, Lengle Desjardins L, et al. Plasma beta-2 microglooulin is associated w cardiovascular disease in uremic patients. Kidney Int. 2012;82(12):1297-1303. doi:10.1038/ki.2012.301

1. Spanaus KS Kollerits B, Ritz E, et al. Serum creatinine, cystatin C, and beta-tra protein in diagnostic staging and predicting progresof of nary nondiabetic chronic kidney disease. Clin Chem. 2010, o):740-749. doi:10.1373/clinchem.2009.138826

Rahman M, Smith MC. Chronic renal insufficiency: a diagnostic and In rapeutic approach. Arch Intern Med. 1998;158(16):1743-1752. doi:10.1001/archinte.158.16.1743

23. Knight EL, Verhave JC, Spiegelman D, et al. Factors influencing serum cystatin $\mathrm{C}$ levels other than renal function and the impact on renal function measurement. Kidney Int. 2004;65(4):1416-1421. doi:10.1111/j.1523-1755.2004.00517.x

24. Bianchi C, Donadio C, Tramonti G, et al. Reappraisal of serum beta2-microglobulin as marker of GFR. Ren Fail. 2001;23(3-4):419-429. doi:10.1081/JDI-100104725

25. Stevens LA, Schmid CH, Greene T, et al. Factors other than glomerular filtration rate affect serum cystatin C levels. Kidney Int. 2009;75 (6):652-660. doi:10.1038/ki.2008.638

26. Vaidya VS, Ramirez V, Ichimura T, Bobadilla NA, Bonventre JV. Urinary kidney injury molecule-1: a sensitive quantitative biomarker for early detection of kidney tubular injury. Am J Physiol Renal Physiol. 2006;290(2):F517-29. doi:10.1152/ajprenal.00291.2005

27. Parikh CR, Mishra J, Thiessen-Philbrook H, et al. Urinary IL-18 is an early predictive biomarker of acute kidney injury after cardiac surgery. Kidney Int. 2006;70(1):199-203. doi:10.1038/sj.ki.5001527

28. Mishra J, Dent C, Tarabishi R, et al. Neutrophil gelatinase-associated lipocalin (NGAL) as a biomarker for acute renal injury after cardiac surgery. Lancet. 2005;365(9466):1231-1238. doi:10.1016/S0140-6736(05)74811-X

29. Wang Y, Wang J, Su T, et al. Community-acquired acute kidney injury: a Nationwide Survey in China. Am J Kidney Dis. 2017;69 (5):647-657. doi:10.1053/j.ajkd.2016.10.034

30. Schanstra JP, Zurbig P, Alkhalaf A, et al. Diagnosis and prediction of CKD progression by assessment of urinary peptides. J Am Soc Nephrol. 2015;26(8):1999-2010. doi:10.1681/ASN.2014050423

31. Siwy J, Schanstra JP, Argiles A, et al. Multicentre prospective validation of a urinary peptidome-based classifier for the diagnosis of type 2 diabetic nephropathy. Nephrol Dial Transplant. 2014;29 (8):1563-1570. doi:10.1093/ndt/gfu039 
32. Wan J, Wang Y, Cai G, et al. Elevated serum concentrations of HE4 as a novel biomarker of disease severity and renal fibrosis in kidney disease. Oncotarget. 2016;7:67748-67759. doi:10.18632/oncotar get. 11682

33. Nagy BJ, Krasznai ZT, Balla H, et al. Elevated human epididymis protein 4 concentrations in chronic kidney disease. Ann Clin Biochem. 2012;49(4):377-380. doi:10.1258/acb.2011.011258

34. Urban N, Thorpe J, Karlan BY, et al. Interpretation of single and serial measures of HE4 and CA125 in asymptomatic women at high risk for ovarian cancer. Cancer Epidemiol Biomarkers Prev. 2012;21 (11):2087-2094. doi:10.1158/1055-9965.EPI-12-0616

35. Chhikara N, Saraswat M, Tomar AK, et al. Human epididymis protein-4 (HE-4): a novel cross-class protease inhibitor. PLoS One. 2012;7(11):e47672. doi:10.1371/journal.pone.0047672

36. Doumas S, Kolokotronis A, Stefanopoulos P. Anti-inflammatory and antimicrobial roles of secretory leukocyte protease inhibitor. Infect Immunol. 2005;73(3):1271-1274. doi:10.1128/IAI.73.3.1271-127 4.2005
37. de Boer RA, Cao Q, Postmus D, et al. The WAP four-disulfide core domain protein HE4: a novel biomarker for heart failure. JACC Heart Fail. 2013;1(2):164-169. doi:10.1016/j.jchf.2012.11.005

38. Piek A, Meijers WC, Schroten NF, et al. HE4 serum levels are associated with heart failure severity in patients with chronic heart failure. J Card Fail. 2017;23(1):12-19. doi:10.1016/j.cardfail.20 16.05.002

39. Bunnag S, Einecke G, Reeve J, et al. Molecular correlates of renal function in kidney transplant biopsies. J Am Soc Nephrol. 2009;20 (5):1149-1160. doi:10.1681/ASN.2008080863

40. Lebleu VS, Teng Y, O'Connell JT, et al. Identification of human epididymis protein-4 as a fibroblast-derived mediator of fibrosis. Nat Med. 2013;19(2):227-231. doi:10.1038/nm.2989

41. Bingle CD, Vyakarnam A. Novel innate immune functions of the whey acidic protein family. Trends Imm 2008;29:444-453. doi:10.1016/j.it.2008.07.001

42. Allison SJ. Fibrosis: HE4-a biomar and target in nal fibrosis. Nat Rev Nephrol. 2013;9:124.

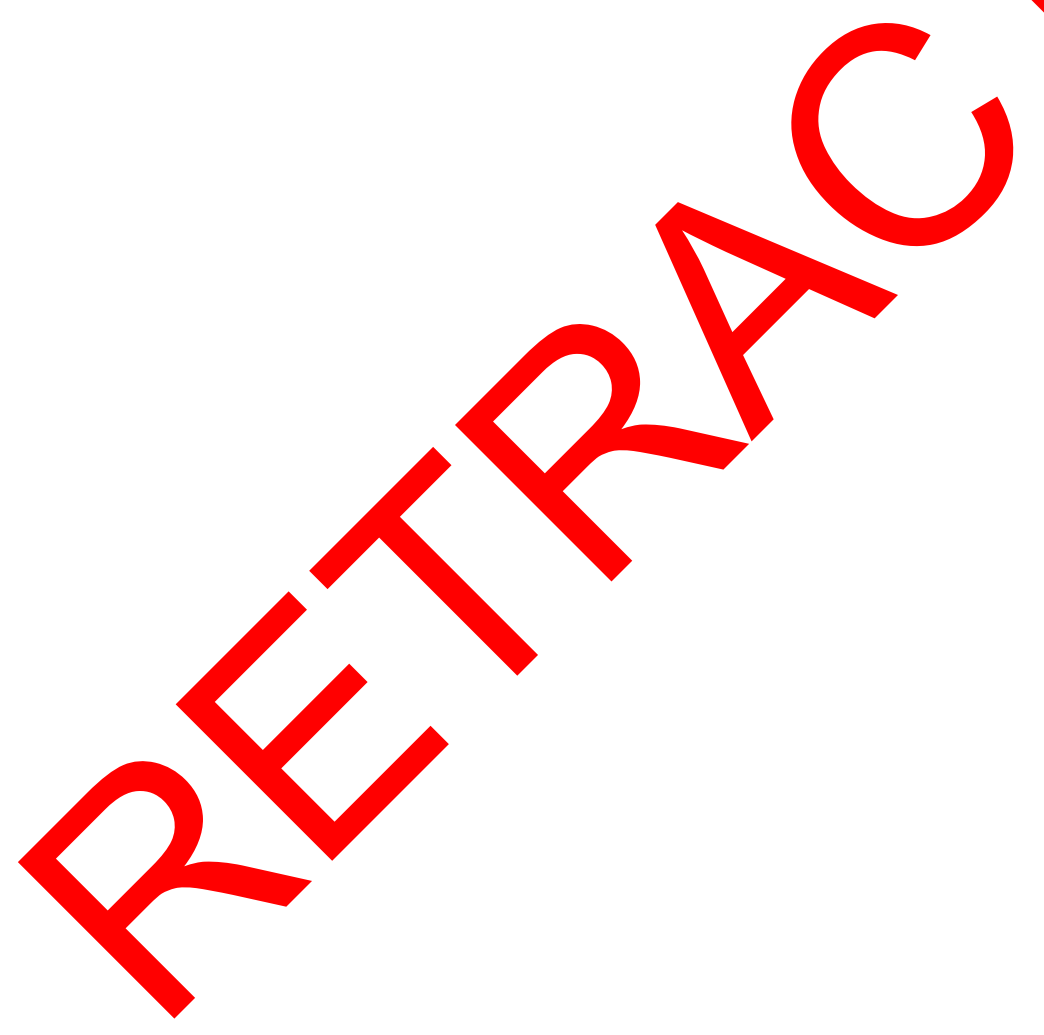

Diabetes, Metabolic Syndrome and Obesity: Targets and Therapy

Dovepress

\section{Publish your work in this journal}

Diabetes, Metabolic Syndrome and Obesity: Targets and Therapy is an international, peer-reviewed open-access journal committed to the rapid publication of the latest laboratory and clinical findings in the fields of diabetes, metabolic syndrome and obesity research. Original research, review, case reports, hypothesis formation, expert opinion and commentaries are all considered for publication. The manuscript management system is completely online and includes a very quick and fair peer-review system, which is all easy to use. Visit http://www.dovepress.com/testimonials.php to read real quotes from published authors.

Submit your manuscript here: https://www.dovepress.com/diabetes-metabolic-syndrome-and-obesity-targets-and-therapy-journal 